\title{
Antihypertensive therapy: nocturnal dippers and nondippers. Do we treat them differently?
}

This article was published in the following Dove Press journal:

Vascular Health and Risk Management

22 March 2013

Number of times this article has been viewed

\section{Chakrapani Mahabala' \\ Padmanabha Kamath ${ }^{2}$ \\ Unnikrishnan Bhaskaran ${ }^{3}$ \\ Narasimha D Pai ${ }^{2}$ \\ Aparna U Pai ${ }^{4}$ \\ 'Department of Medicine, Kasturba Medical College, Manipal University, Mangalore, Karnataka State, India; \\ ${ }^{2}$ Department of Cardiology, Kasturba Medical College, Manipal University, \\ Mangalore, Karnataka State, India; ${ }^{3}$ Department of Community Medicine, Kasturba Medical College, Manipal University, Mangalore, Karnataka State, India; ${ }^{4}$ Department of Radiodiagnosis, Vivekananda Institute of Medical Sciences, Kolkata, West Bengal State, India}

Correspondence: Chakrapani Mahabala Department of Medicine, Kasturba Medical College, Manipal University, Light House Hill Road,

Mangalore 57500I, India

Tel +9| 94 488| 2207

Email chakrapani.m@manipal.edu
Abstract: Hypertension is a major independent risk factor for cardiovascular diseases. Management of hypertension is generally based on office blood pressure since it is easy to determine. Since casual blood pressure readings in the office are influenced by various factors, they do not represent basal blood pressure. Dipping of the blood pressure in the night is a normal physiological change that can be blunted by cardiovascular risk factors and the severity of hypertension. Nondipping pattern is associated with disease severity, left ventricular hypertrophy, increased proteinuria, secondary forms of hypertension, increased insulin resistance, and increased fibrinogen level. Long-term observational studies have documented increased cardiovascular events in patients with nondipping patterns. Nocturnal dipping can be improved by administering the antihypertensive medications in the night. Long-term clinical trials have shown that cardiovascular events can be reduced by achieving better dipping patterns by administering medications during the night. Identifying the dipping pattern is useful for decisions to investigate for secondary causes, initiating treatment, necessity of chronotherapy, withdrawal or reduction of unnecessary medications, and monitoring after treatment initiation. Use of this concept at the primary care level has been limited because 24-hour ambulatory blood pressure monitoring has been the only method for documenting dipping/nondipping status so far. This monitoring technique is expensive and inconvenient for routine usage. Simpler methods using home blood pressure monitoring systems are evolving to document basal blood pressure in the night, which would help in greater acceptance and use of the concept of dipper/nondipper in managing hypertension at the primary care level.

Keywords: 24-hour ambulatory blood pressure monitoring, blood pressure variability, left ventricular hypertrophy, chronotherapy

\section{Introduction}

Hypertension is a major independent risk factor for cardiovascular diseases. Management of hypertension is generally based on office blood pressure (BP) readings. Since casual BP readings in the office are influenced by various factors, they do not represent basal BP. Dipping of BP in the night is a normal physiological change that can be blunted by cardiovascular risk factors and the severity of hypertension. Reduced nocturnal dipping of BP can have profound impact in the overall treatment strategy of hypertension. In this review, differences between dippers and nondippers in terms of severity of the disease, association with cardiovascular risk factors, extent of target organ damage, and long-term outcomes are discussed. Treatment strategies to improve dipping status, as well as newer and simpler methods to identify dipping status are discussed. 


\section{Importance of identifying high risk hypertensives}

Hypertension treatment has evolved over a period of time with a gradual shift from a step care regimen based on BP alone, to total risk-based assessment and management. Recent guidelines on the treatment of hypertension have highlighted the importance of assessing the associated risk factors and the presence and extent of target organ damage along with BP measurements to decide the initiation of treatment and drug selection. ${ }^{1}$ Antihypertensive treatment leads to significant reduction in relative risk of cardiovascular events, though the number of patients needed to be treated (NNT) to prevent one cardiovascular event is substantially high, especially when the disease is mild. In a meta-analysis of 147 trials, the relative risk reduction of coronary artery disease was $21 \%$ over a mean of 4.6 years, for a BP reduction of 10/5 (systolic/diastolic) $\mathrm{mmHg}$, among patients without any cardiovascular disease with a pretreatment systolic BP of $132-186 \mathrm{mmHg} .{ }^{2}$ But the NNT to prevent one event works out to around 140 . This number will be larger if stage one hypertensives are considered. The goal of assessment and risk stratification is to identify high-risk hypertensive patients who would derive the maximum benefit from treatment compared to low risk hypertensives whose benefit from antihypertensive treatment may not be favorable in terms of risk benefit ratio, considering the long-term treatment side effects. While presence of target organ damage is a definite indication for initiating treatment, physicians have been looking for simpler clinical tools to identify high-risk individuals. BP that does not dip down to the normal physiological range during the night has been identified as a reliable indicator of increased cardiovascular complications in the future, and is emerging as an independent and powerful marker for highrisk hypertensive patients. ${ }^{3}$

\section{Concept of dipper and nondipper}

In healthy individuals BP follows a circadian pattern. BP starts declining from late evening onwards, reaches a nadir around midnight, and shoots up just after awakening in the morning. ${ }^{4}$ Dips in BP have been described in three windows of sleep: BP starts declining in the vesperal window, reaches the plateau level in the basal window, rises in the preawakening window. ${ }^{5}$ This phenomenon of BP dipping has been documented by 24-hour ambulatory BP monitoring (ABPM) devices. This natural circadian variation may be altered by certain metabolic and cardiovascular changes. ${ }^{6}$

Initial observations regarding the nondipping pattern of $\mathrm{BP}$ and complications due to hypertension were documented by O'Brien about four decades ago. ${ }^{7} \mathrm{~A}$ fall of $>10 \%$ in systolic and diastolic BP in the night, compared to daytime readings, is normal. Patients with a nocturnal fall $<10 \%$ are defined as nondippers, ${ }^{3}$ and those with a paradoxical rise in the night reading are defined as reverse dippers. The important concept regarding basal and casual BP and the difference being supplemental BP was propounded by Smirk in 1964. ${ }^{5}$ Smirk observed that basal BP was a relatively constant physiological parameter, unlike casual BP obtained in the office. Even in the absence of provoking environmental situations during the awakening period, BP is not constant. ${ }^{8}$ Dependence on the clinical measurement of BP significantly overestimated the hypertensive status when compared to 24-hour ABPM. ${ }^{9}$ A meta-analysis of 20 studies suggests that if ABPM is taken as the reference standard for the detection of hypertension, clinic measurements over $140 / 90 \mathrm{mmHg}$ had a sensitivity of $74.6 \%$ (95\% confidence interval $60.7 \%$ to $84.8 \%$ ) and a specificity of $74.6 \%$ ( $95 \%$ confidence interval $47.9 \%$ to $90.4 \%$ ). ${ }^{9}$ Night BP represents basal BP and hence is representative of the true BP status of an individual. ${ }^{5}$ Blunting of normal physiological dipping of the BP in the night should be considered abnormal and investigated. ${ }^{3}$ Office BP is affected by random error, systematic error, and a patient's alerting response in addition to numerous other physiological variables during the daytime. ${ }^{10}$ Out of office recordings of the $\mathrm{BP}$ are better than the office recordings since they measure the unstimulated basal BP status. ${ }^{11}$ In fact, even normotensives showing the nondipping pattern of $\mathrm{BP}$ are at a higher risk of cardiovascular complications. ${ }^{8}$

\section{Association of nondippers with risk factors and target organ damage}

Nondipping BP patterns can be a useful marker of hypertension severity, if they are proven to be associated with other risk factors and complications. Daytime BP does not add prognostic precision compared to the same information provided by nighttime BP. Nondipping status is associated with the need for more antihypertensive drugs for control, suggesting that a nondipping pattern can identify severe disease. ${ }^{12}$

A nondipping pattern is associated with cardiovascular risk factors, target organ damage, and risk of future cerebrovascular events and secondary hypertension. ${ }^{3}$ Left ventricular hypertrophy $(\mathrm{LVH})$, carotid intima-media thickening, microalbuminuria, and cerebrovascular diseases are much more prevalent in nondippers. ${ }^{3}$ Circadian analysis correlates better with surrogate markers of vascular disease than office BP readings. ${ }^{13}$ Insulin resistance, which is an important cardiovascular risk factor, has been associated 
with BP nondipping. In a cross-sectional study involving 103 hypertensive subjects with comparable daytime BP readings, the homeostasis model assessment index for insulin resistance was higher in nondippers compared to dippers $(2.0 \pm 0.3$ versus $1.4 \pm 0.3, P<0.0001) .{ }^{14} \mathrm{LVH}$, atrial natriuretic peptide, and brain natriuretic peptide were also statistically significantly elevated in nondippers.

In a cross-sectional observational study of 84 untreated hypertensive patients, pulse wave velocity was higher among nondippers compared to dippers, $(8.91 \pm 2.53 \mathrm{~m} / \mathrm{second}$ versus $7.66 \pm 1.08 \mathrm{~m} / \mathrm{second}, P=0.002$ ), suggesting increased arterial stiffness in nondippers. ${ }^{15}$ Red cell distribution width, which is closely related to adverse cardiovascular outcomes, was higher in nondippers compared to dippers $(14.1 \% \pm 1.33 \%$ versus $13.5 \% \pm 0.89 \%, P=0.008) .{ }^{16}$ Oxidative stress is higher in nondippers compared to dippers as evidenced by increased levels of asymmetric dimethyl arginine among nondippers $(P<0.01) .{ }^{17}$ Mean platelet volume, which is a determinant of platelet activation, was higher among nondippers compared to dippers $(9.72 \pm 0.52 \mathrm{fL}$ versus $9.38 \pm 0.33 \mathrm{fL}, P<0.05) .{ }^{18}$ Inflammatory markers, such as c-reactive protein, were also higher among nondippers. ${ }^{18,19}$

Nocturnal sodium excretion is increased in nondippers..$^{20}$ Persistence of daytime BP into the night and the development of a nondipper state appear to be secondary to the necessity for extended pressure natriuresis. The role of autonomic systems appears to be limited. Many patients with autonomic failure still maintain normal dipping pattern of BP in the night. ${ }^{20}$ There have been some concerns regarding extreme dippers and silent stroke; for instance, strokes are related to the early morning BP surges, but this appears to be independent of nocturnal dipping. ${ }^{21}$

Analysis of 42,947 hypertensive patients included in the Spanish Society of Hypertension Ambulatory Blood Pressure Monitoring Registry revealed that age, obesity, diabetes, and overt cardiovascular and renal diseases were associated with blunted nocturnal BP decline $(P<0.001) .{ }^{12}$ The nondipping BP pattern was observed in $>70 \%$ of elderly, diabetic, secondary, and resistant hypertensive patients. ${ }^{8,22}$ Nondipping has been associated with other known cardiovascular risk factors, like fibrinogen level, which has been a recognized marker for potential cardiovascular events. ${ }^{23}$ In an observational study involving 1006 patients that studied the seasonal variation in the levels of fibrinogen over 2.5 years, fibrinogen levels were consistently and significantly less in dippers $(P=0.003)$ even after correcting for confounders like physical activity, smoking, alcohol consumption, gender, and antihypertensive medication. ${ }^{23}$ Cardiovascular risk is influenced not only by BP elevation, but also by the abnormal circadian BP variability.

BP measured in the office does not have a good correlation with LVH compared to out of office recordings, whereas sleep BP appears to be reliable in predicting target organ damage. Although a meta-analysis of 19 studies did not show any superiority of night over day BP for correlating with left ventricular mass, ${ }^{24}$ many other studies did find impressive correlations between nocturnal BP and LVH compared to daytime readings. ${ }^{14,25,26}$ Verdecchia et al have shown that night recordings correlate well with echocardiographic left ventricular mass in 235 individuals compared to daytime and casual recordings (nighttime systolic $r=0.51$ and diastolic $\mathrm{r}=0.35$, daytime systolic $\mathrm{r}=0.38$ and diastolic $\mathrm{r}=0.20$, casual systolic $r=0.33$ and diastolic $r=0.27) .{ }^{25}$ Good correlations between LVH and BP in the night have been observed in others studies too (Table 1). 14,26,27

\section{Long-term outcomes}

The long-term follow-up of the prognostic value of ambulatory and home BPs compared with office BP in the general population (Pressioni Arteriose Monitorate e Loro Associazioni [PAMELA] study) provides evidence for the superiority of night over daytime values. ${ }^{28}$ In this study, 2051 subjects were followed for 131 months with baseline office BP, home BP, and 24-hour ABPM. A total of 186 cardiovascular and noncardiovascular fatal events were observed during this period. Office, home, and 24-hour ABPM showed a significant exponential direct relationship with risk of cardiovascular or all cause death, but the goodness of fit of the relationship was superior for night rather than for day BP.

Long-term observational studies have established the fact that nondippers have worse outcomes in terms of cardiovascular events compared to dippers. Only nighttime $\mathrm{BP}$ was associated with the development of cardiovascular diseases, whereas BP during waking could not predict the

Table I Correlation coefficients ( $r$ ) for systolic and diastolic BPs with left ventricular hypertrophy

\begin{tabular}{lll}
\hline & Systolic & Diastolic \\
\hline Average ambulatory & $0.5 \mathrm{I}$ & 0.35 \\
BP night $^{25}$ & $(P<0.0 \mathrm{I})$ & $(P<0.0 \mathrm{I})$ \\
Average ambulatory $_{\text {BP night }}^{26}$ & 0.275 & 0.243 \\
Night home monitored $^{27}$ & $(P<0.0 \mathrm{I})$ & $(P<0.05)$ \\
& 0.66 & 0.496 \\
Average ambulatory $_{\text {BP night }}{ }^{14}$ & $(P<0.00 \mathrm{I})$ & $(P<0.005)$ \\
\hline
\end{tabular}

Abbreviation: BP, blood pressure. 
future onset of cardiovascular diseases. ${ }^{29}$ Hypertensives with preserved normal dipping pattern show a higher probability of cardiovascular disease (CVD) event-free survival and lower CVD mortality risk compared to nondippers on long-term follow-up.

Prognostic value of dipping pattern was established by Verdecchia et al in a long-term follow-up study. A total of 715 essential hypertensive patients that underwent ABPM were followed up over 1-13 years. Relative risk of cardiovascular events was 2.77 (95\% confidence interval 1.12-6.83) in nondippers compared to dippers $(P<0.05) .{ }^{30,31}$ In the Ohasama ${ }^{32}$ study, the prognostic significance of the nocturnal decline in BP was studied by following up 1542 residents of Ohasama, Japan, who were 40 years of age or older, for a mean of 9.2 years. On average, a 20\% greater risk of cardiovascular mortality was noted for each 5\% decrease in nocturnal BP dipping. ${ }^{32}$ Even when 24-hour average BP values were within the normal range (average 118/69 $\mathrm{mmHg}$ ), diminished nocturnal decline in BP was associated with an increased risk of cardiovascular mortality. ${ }^{32}$ In the Dublin outcome study, 5292 patients were followed up over a median of 8.4 years. Office and ABPM were recorded at the beginning of the study and 646 deaths were noted during the follow-up. Higher mean values of ambulatory BP were independent predictors for cardiovascular mortality. The relative hazard ratio for each $10 \mathrm{mmHg}$ increase in systolic BP was 1.12 (1.06 to 1.18 ; $P<0.001)$ for daytime and 1.21 (1.15 to $1.27 ; P<0.001)$ for nighttime systolic BP. ${ }^{33}$ For each $10 \mathrm{mmHg}$ increase in mean nighttime systolic BP, the mortality risk increased by $21 \% .^{5}$ In a subanalysis of the Systolic Hypertension in Europe study involving 808 older untreated isolated systolic hypertensives, for every $10 \%$ higher night to day ratio of systolic BP, the hazard ratio for total cardiovascular events was 1.41 (95\% confidence interval $1.03-1.94 ; P=0.03)$ even after controlling for confounders. ${ }^{34}$ Hence, the night to day ratio of systolic ambulatory $\mathrm{BP}$ was an independent predictor of cardiovascular events. ${ }^{13}$ Outcomes of cardiovascular events from these long-term observational studies are shown in Table 2.
Prognostic significance of night/day ratio for mortality in hypertensives without major events at baseline was analyzed in a meta-analysis of four prospective studies involving 3468 patients followed for a total of 23,164 patient years. ${ }^{35}$ Reverse dippers had statistically significant higher cardiovascular events $(P<0.05)$ than dippers. Hazards ratio for reverse dippers was $1.62(1.22-2.15)$ compared to dippers. ${ }^{35}$ In another small study involving 30 treatment-naïve hypertensive subjects, seven were found to have reverse dipping by home monitoring of BP during the night, and all of them were found to have LVH. ${ }^{27}$

Circadian changes in BP are prognostic markers of cardiovascular events among those with normal BP as well. ${ }^{12}$ When compared to normotensive dippers, dipper hypertensive subjects as well as nondipper normotensive subjects had a similar relative hazard of cardiovascular mortality (2.37). ${ }^{36}$ These nondipper normotensives can only be identified by 24-hour ABPM or other methods of recording the sleep BP, and may not receive antihypertensive treatment despite higher cardiovascular risk if their dipping status is not assessed.

It is clear that dippers and nondippers are different in their cardiovascular risk profile, severity of the disease, end organ involvement, and long-term cardiovascular complications. Therefore, it makes sense to segregate and risk-stratify hypertensives based on dipping pattern. Identifying and managing nondippers among hypertensives, who would derive maximum benefit by aggressive treatment, assumes greater significance. $^{23}$

\section{Improving dipping pattern: is it possible and useful?}

Although a strong association between nondippers and cardiovascular complications exists, the next step is to show that reversing this pattern reduces these complications. The possibility of converting nondippers to dippers using telmisartan administered at night was assessed in a study of 215 patients who were randomized to $80 \mathrm{mg}$ telmisartan in the morning or evening. After 12 weeks of treatment, overall

Table 2 Cardiovascular outcomes in long-term observational studies with respect to dipping status of BP

\begin{tabular}{llll}
\hline Study & Number of patients & Follow-up & Outcome \\
\hline Verdecchia et a ${ }^{30}$ & 715 & $1-13$ years & $\begin{array}{l}\text { Relative risk of cardiovascular events was } 2.77 \\
\text { in nondippers compared to dippers }\end{array}$ \\
Ohasama study $^{32}$ & 1542 & 9.2 years & $\begin{array}{l}20 \% \text { greater risk of cardiovascular mortality for } \\
\text { every 5\% reduction in decline of nocturnal BP } \\
\text { Dublin outcome study }{ }^{33}\end{array}$ \\
& 5292 & 8.4 years & $\begin{array}{l}\text { Hazard ratio for cardiovascular mortality was } \\
\text { 1.2I for each } 10 \text { mmHg higher night systolic BP }\end{array}$ \\
\hline
\end{tabular}

Abbreviation: BP, blood pressure. 
BP control was similar, but night dose reduced nondipping by $76 \%$ without loss in 24-hour efficacy. ${ }^{37}$

Small studies have documented the reduction in microalbuminuria when dipping pattern was restored. In a small study involving 31 subjects, the efficacy and safety of the bedtime administration of amlodipine-olmesartan combination therapy, as compared with the morning administration, was evaluated by measuring the albumin/creatinine ratio as a marker of target organ damage. The bedtime administration reduced the morning systolic BP surge significantly $(24.2 \pm 13.5 \mathrm{mmHg}$ versus $32.3 \pm 14.2 \mathrm{mmHg}, P<0.001)$. Urinary albumin/creatinine ratio was lower in the bedtime administration than in the morning administration $(42.5 \pm 59.9 \mathrm{mg} / \mathrm{g}$ versus $75.3 \pm 26.4 \mathrm{mg} / \mathrm{g}, P=0.044){ }^{38}$

In a study of 200 hypertensive patients, overall BP remained similar in the two groups assigned to receive valsartan (160 mg/day) as a monotherapy, either on awakening or at bedtime after 3 months of treatment. The diurnal/ nocturnal BP ratio significantly improved $(P<0.001)$ in the night administered group. Protein excretion reduced by $41 \%$ in patients receiving the medication in the night, which correlated with diurnal/nocturnal ratio but not the 24-hour BP. ${ }^{36}$ Similar observations were noted in another study involving 148 nondipper patients who were randomly assigned to receive valsartan (160 $\mathrm{mg} /$ day) either on awakening or at bedtime; $75 \%$ of those given the medication in the night became dippers again, along with statistically significant reduction in microalbuminuria, despite a comparable 24-hour mean BP after 3 months of treatment (Table 3). ${ }^{39}$

\section{Chronotherapy to improve dipping pattern}

Multiple studies have confirmed that it is possible to achieve a dipping pattern by administering antihypertensives in the night. Chronotherapy of hypertension is emerging as a new therapeutic option and benefits have been established in long term studies with clinical outcomes as end points.
In the Syst-Eur substudy, nitrendipine in the night converted a significant number of nondippers to dipper status. ${ }^{34}$ In the Heart Outcomes Prevention Evaluation (HOPE) study, ramipril administered in the night demonstrated decreased CVD risk by controlling night $\mathrm{BP}^{8}$ In this study, the use of ramipril was associated with a $22 \%$ relative risk reduction in cardiovascular death, myocardial infarction, or stroke, despite a modest reduction in $\mathrm{BP}(3 / 2 \mathrm{mmHg}){ }^{40}$ Benefits seen in HOPE were approximately three times greater than predicted from the previous studies, based on BP reduction alone. ${ }^{40}$ Ramipril was administered in the night in this study unlike the previous studies where antihypertensive drugs were administered in the morning. Although reduction in the daytime BP was quite modest with ramipril, the reduction in cardiovascular endpoints was much more than what would have been achieved with daytime BP reduction alone. In a HOPE substudy, 38 patients with peripheral vascular disease underwent ABPM before randomization and after 1 year of treatment with $10 \mathrm{mg}$ ramipril given in the night. There was no statistically significant reduction in office BP $(8 / 2 \mathrm{mmHg}, P=$ nonsignificant $)$ or day ambulatory BP (6/2 $\mathrm{mmHg}, P=$ nonsignificant), but a significant reduction in nighttime BP $(17 / 8 \mathrm{mmHg}, P<0.001)$ was observed. ${ }^{41}$ Antihypertensives administered in the evening, which resulted in a fall in night BP, might have been the cause of the spectacular benefit observed in HOPE. ${ }^{6,42}$ It has been estimated that an $8 \%$ difference in the night/day ratio between the placebo and ramipril groups (0.89 and 0.82$)$ might have contributed to the additional cardiovascular event reduction..$^{23,41}$

The effect of chronotherapy in achieving overall BP control for combination of valsartan and amlodipine was also studied. For instance, 203 hypertensives were randomized to a combination of valsartan and amlodipine either in the morning or night, in one of four combinations. Fortyeight hour mean systolic and diastolic BP were reduced significantly when both were given in the night compared to other combinations. ${ }^{43}$ The reduction was $17.4 / 13.4 \mathrm{mmHg}$

Table 3 Improvement in proteinuria by improving dipping pattern

\begin{tabular}{|c|c|c|c|c|}
\hline Study & Number of patients & Intervention & Duration & Outcome \\
\hline Hermida et al $2005^{36}$ & 200 & $\begin{array}{l}\text { Valsartan } 160 \mathrm{mg} \text { morning or } \\
\text { evening }\end{array}$ & 3 months & $\begin{array}{l}\text { Protein excretion reduced by } \\
41 \% \text { in those receiving night dose }\end{array}$ \\
\hline Hermida et al $2005^{39}$ & I48 nondippers & $\begin{array}{l}\text { Valsartan } 160 \mathrm{mg} \text { morning or } \\
\text { evening }\end{array}$ & 3 months & $\begin{array}{l}75 \% \text { of those receiving night dose } \\
\text { became dippers with reduction } \\
\text { of proteinuria }\end{array}$ \\
\hline Hoshino et $\mathrm{al}^{38}$ & 31 & $\begin{array}{l}\text { Amlodipine-Olmesartan } \\
\text { combination - morning or } \\
\text { evening }\end{array}$ & 8 weeks & $\begin{array}{l}\text { Urinary albumin/creatinine ratio } \\
\text { was } 42.5 \pm 59.9 \mathrm{mg} / \mathrm{g} \text { versus } \\
75.3 \pm 26.4 \mathrm{mg} / \mathrm{g} \text { in bedtime } \\
\text { versus daytime administration }\end{array}$ \\
\hline
\end{tabular}


with both medications on awakening; 15.1/9.6 mmHg with valsartan on awakening and amlodipine at bedtime; 18.2/12.3 $\mathrm{mmHg}$ with valsartan at bedtime and amlodipine on awakening; and $24.7 / 13.5 \mathrm{mmHg}$ with both medications administered at bedtime ( $P<0.018$ between groups). ${ }^{43}$ This study established that for a given dose and combination of antihypertensives, administering them in the night results in better reduction of nocturnal BP than when they are given in the morning.

Although results of the HOPE study highlighted the importance of dosing the medication at night, there was no direct comparison with daytime dosing in that study. The MAPEC study (Monitorización Ambulatoria para Predicción de Eventos Cardiovasculares; Ambulatory Blood Pressure Monitoring for Prediction of Cardiovascular Events) specifically addressed this issue. MAPEC compared morning versus night doses and concluded that the night dose achieved better overall BP control after a mean follow-up of 5.6 years in 2156 individuals. ${ }^{6}$ Subjects were randomized to all medicines in the morning or one or more in the evening. Though there was no difference in 24-hour mean ambulatory BP, subjects ingesting more than one drug in the night showed significantly lower relative risk of total CVD events 0.39 (0.29-0.51; $P<0.001)$, compared to those ingesting all drugs in the morning. ${ }^{22}$ The prevalence of nondipping significantly reduced in those receiving medication in the night $(34 \%$ versus $62 \% ; P<0.001) .{ }^{8}$ This was the first study to demonstrate a reduction in clinical end points by achieving a better dipping pattern by dosing the medication in the night compared to administering it in the morning. It was suggested that it would be inappropriate to treat all hypertensive subjects using the same morning, once a day dosing strategy. In addition, chronotherapy was found to be useful in resistant hypertension. In a study of 250 resistant hypertensives on three drugs, ${ }^{44}$ ambulatory BP reduced by 9.4/6.0 $\mathrm{mmHg}(P<0.001)$ when one drug was administered at bed time. The percentage of dippers rose from $16 \%$ to $57 \%$ after 12 weeks of adding one drug at night. ${ }^{44}$

\section{Monitoring of treatment based on dipper/nondipper concept}

Improvement of cardiovascular prognosis after initiation of antihypertensive treatment is more closely related with changes in 24-hour BP than with office BP. ${ }^{45}$ Treatment, using ABPM for monitoring is better than treatment based on casual BP in controlling BP with fewer drugs and is cost effective. ${ }^{45}$ Monitoring of treatment based on dipping patterns led to more drug withdrawal among 419 patients randomized to ABPM based or office BP based treatment (26.3\% versus $7.3 \% ; P<0.001$ ), after a median follow-up of 182 days, and fewer ABPM patients had progressed to multiple-drug treatment $(27.2 \% \text { versus } 42.7 \% ; P<0.001)^{13,46}$

Looking for dipping patterns has been suggested as part of hypertension treatment guidelines. Canadian guidelines issued in 2009 advised clinicians to consider the magnitude of the nocturnal BP dip, as patients "dipping less than $10 \%$ at night are at increased CVD risk". ${ }^{47,48}$ It is also suggested that one or more antihypertensive medications be given in the night, though this was not a strong recommendation. ${ }^{47}$

Since nondippers derive more benefit from a bedtime as opposed to a morning dosing schedule of antihypertensive medications than dippers, identifying the dipping status would be appropriate for bedtime dosing strategy. $22,37,38$ Evening dosing of antihypertensive medication improves nocturnal dipping of BP while maintaining effective 24-hour control. ${ }^{6}$ Bedtime administration of amlodipine-olmesartan significantly improved nocturnal dipping of BP in nondippers, while it did not reduce nocturnal BP in dippers. ${ }^{38}$ Administration of antihypertensive medications could be guided by dipping status. These observations suggest that dippers and nondippers should be managed differently.

\section{Limitations of present methods to detect nondippers and new options}

Although it is evident that nondipping is an important indication for initiating treatment and that chronotherapy to reverse it back to a dipping pattern is feasible and useful, there are logistical issues in implementing it as, until recently, 24-hour ABPM was the only objective way to document nocturnal dip. ${ }^{49}$ This process involves expensive equipment and software, as well as disturbance of normal sleep, which precludes its use in primary care settings. ${ }^{49,50}$ Home BP monitoring equipment is simple, convenient, and is useful to detect white coat hypertension, but it has not been widely used nor validated for documenting nocturnal dipping patterns. ${ }^{49}$ Recently, simple and inexpensive alternative methods to document night BP have been explored and have shown promising results. For instance, a novel home $\mathrm{BP}$ monitoring system to record multiple readings during the day and night has been compared with ABPM and showed excellent agreement in the recorded pressures and in dipping patterns. ${ }^{51}$ This study compared ABPM and home BP monitoring for nocturnal BP in 81 hypertensives within an interval of 2 weeks. Strong associations were found between $\mathrm{ABPM}$ and home BP (intraclass correlation coefficients for awake systolic/diastolic $0.75 / 0.81$; asleep $0.87 / 0.85$ ) and 
there was substantial agreement (74\%, kappa 0.2$)$ between ABPM and home BP for the detection of nondippers. ${ }^{51}$ Thus, the major obstacle for implementing the concept of dipper/ nondipper in managing hypertension is potentially overcome, and these home BP monitors, which are very convenient and user friendly, might be part of routine care of patients.

Taking the average of night recordings at multiple time intervals over many hours, as is the present practice in 24-hour ABPM, may not reflect the basal BP since it gets diluted by other readings obtained during the vesperal window before subsequently reaching the plateau and preawakening window. Reproducibility of the results of 24-hour ambulatory BP recordings are poor, and the selection of appropriate timing for recording nocturnal $\mathrm{BP}$, with respect to sleep, has been problematic due to the variability of $\mathrm{BP}^{52}$ Basal $\mathrm{BP}$ recordings taken during the basal window of sleep have shown a superior correlation with $\mathrm{LVH}$ than the conventional average night recordings using ABPM. ${ }^{50}$ We have shown that $\mathrm{BP}$ recordings taken in the night in the homes of patients using electronic home BP recorders, by the patients' attendants after 3 hours of sleep, correlated well with LVH. ${ }^{27}$ The correlation coefficient was comparable or better than the values recorded in previous studies using ABPM (Table 1). However, only 30 subjects were studied in this small study. A shift from ABPM to other simpler and novel methods of documenting night BP during the basal window of sleep may hold the future for differentiating dippers from nondippers with the hopes of managing them appropriately. These simpler methods can be used for monitoring the efficacy of treatment at the level of point of care, thereby improving patient compliance and adherence to treatment.

\section{Future studies with dipping status incorporated in the study design needed}

Most of the major studies done so far for the treatment of hypertension have relied upon office recordings. The concept of dipper/nondipper has been used only in a small number of studies. The duration of follow-up in these studies was short. Although improvement in BP dipping pattern and the metabolic parameters have been observed in these studies, benefits in terms of reductions in cardiovascular events have not yet been demonstrated. Despite the impressive results obtained by implementing the dipper/nondipper concept, home BP monitoring to document nocturnal BP needs to be tested in large and long term prospective studies before it can be implemented widely.

\section{Conclusion}

Normal dipping pattern is characterized by a $>10 \%$ dip in the BP during the night. Nondipping pattern is associated with severity of the disease, target organ damage, secondary forms of hypertension, multiple cardiovascular risk factors, and poor long-term outcomes. Identifying nondippers can be accomplished by conventional 24-hour ABPM or other novel and simpler methods to document basal BP during sleep. Identifying the dipping pattern is useful for aiding the decision to investigate for secondary causes, initiating treatment, deciding on the necessity for chronotherapy, withdrawal or reduction of unnecessary medication, and monitoring after treatment initiation. Treatment based on dipper/nondipper status is an emerging novel concept for identifying high risk hypertensive patients who would derive maximum benefit with antihypertensive medication. Antihypertensive medication administered in the night significantly improves the dipping pattern and improves the metabolic profile. However, reductions in cardiovascular end points and mortality risk have not yet been established in large, long-term, prospective, randomized trials. There is a need to refine, simplify, and standardize the method for nocturnal BP recording. Simpler methods are evolving to document the basal BP at night, which would help in greater use of the concept of dipper/nondipper in managing hypertension at the primary care level.

\section{Disclosure}

The authors report no conflicts of interest in this work.

\section{References}

1. Chobanian AV, Bakris GL, Black HR, et al; for National Heart, Lung, and Blood Institute Joint National Committee on Prevention, Detection, Evaluation, and Treatment of High Blood Pressure, National High Blood Pressure Education Program Coordinating Committee. The Seventh Report of the Joint National Committee on Prevention, Detection, Evaluation, and Treatment of High Blood Pressure: the JNC 7 report. JAMA. 2003;289(19):2560-2572.

2. Law MR, Morris JK, Wald NJ. Use of blood pressure lowering drugs in the prevention of cardiovascular disease: meta-analysis of 147 randomised trials in the context of expectations from prospective epidemiological studies. BMJ. 2009;338:b1665.

3. Birkenhäger AM, van den Meiracker AH. Causes and consequences of a non-dipping blood pressure profile. Neth J Med. 2007;65(4):127-131.

4. Pickering TG. The clinical significance of diurnal blood pressure variations. Dippers and nondippers. Circulation. 1990;81(2):700-702.

5. O'Brien E. Sleepers versus nonsleepers: another twist to the dipper/ nondipper concept. Hypertension. 2007;49(4):769-770.

6. Flack JM, Nasser SA. Benefits of once-daily therapies in the treatment of hypertension. Vasc Health Risk Manag. 2011;7:777-787.

7. O’Brien E, Sheridan J, O’Malley K. Dippers and non-dippers. Lancet. 1988;2(8607):397.

8. Portaluppi F, Smolensky MH. Perspectives on the chronotherapy of hypertension based on the results of the MAPEC study. Chronobiol Int. 2010;27(8):1652-1667. 
9. Hodgkinson J, Mant J, Martin U, et al. Relative effectiveness of clinic and home blood pressure monitoring compared with ambulatory blood pressure monitoring in diagnosis of hypertension: systematic review. BMJ. 2011;342:d3621.

10. Parati G, Omboni S, Bilo G. Why is out-of-office blood pressure measurement needed? Home blood pressure measurements will increasingly replace ambulatory blood pressure monitoring in the diagnosis and management of hypertension. Hypertension. 2009;54:181-187.

11. Bursztyn M. Out-of-office blood pressure measurement: a new era. Hypertension. 2005;45(6):1070-1071.

12. de la Sierra A, Redon J, Banegas JR, et al; for Spanish Society of Hypertension Ambulatory Blood Pressure Monitoring Registry Investigators. Prevalence and factors associated with circadian blood pressure patterns in hypertensive patients. Hypertension. 2009;53(3):466-472.

13. Ernst ME, Bergus GR. Ambulatory blood pressure monitoring. South Med J. 2003;96(6):563-568.

14. Anan F, Takahashi N, Ooie T, Yufu K, Saikawa T, Yoshimatsu H. Role of insulin resistance in nondipper essential hypertensive patients. Hypertens Res. 2003;26(9):669-676.

15. Cicek Y, Durakoglugil ME, Kocaman SA, et al. Non-dipping pattern in untreated hypertensive patients is related to increased pulse wave velocity independent of raised nocturnal blood pressure. Blood Press. 2012;22(1):34-38.

16. Gunebakmaz O, Kaya MG, Duran M, Akpek M, Elcik D, Eryol NK. Red blood cell distribution width in 'non-dippers' versus 'dippers'. Cardiology. 2012;123(3):154-159.

17. Gönenç A, Hacışevki A, Tavil Y, Cengel A, Torun M. Oxidative stress in patients with essential hypertension: A comparison of dippers and non-dippers. Eur J Intern Med. Epub September 13, 2012.

18. Kaya MG, Yarlioglues M, Gunebakmaz O, et al. Platelet activation and inflammatory response in patients with non-dipper hypertension. Atherosclerosis. 2010;209(1):278-282.

19. Ermis N, Yagmur J, Acikgoz N, et al. Serum gamma-glutamyl transferase (GGT) levels and inflammatory activity in patients with nondipper hypertension. Clin Exp Hypertens. 2012;34(5):311-315.

20. Okamoto LE, Gamboa A, Shibao C, et al. Nocturnal blood pressure dipping in the hypertension of autonomic failure. Hypertension. 2009; 53(2):363-369.

21. Kario K, Pickering TG, Umeda Y, et al. Morning surge in blood pressure as a predictor of silent and clinical cerebrovascular disease in elderly hypertensives: a prospective study. Circulation. 2003;107(10): 1401-1406

22. Hermida RC, Ayala DE, Mojón A, Fernández JR. Influence of circadian time of hypertension treatment on cardiovascular risk: results of the MAPEC study. Chronobiol Int. 2010;27(8):1629-1651.

23. Hermida RC, Calvo C, Ayala DE, et al. Seasonal variation of fibrinogen in dipper and nondipper hypertensive patients. Circulation. 2003;108(9):1101-1106.

24. Fagard R, Staessen JA, Thijs L. The relationships between left ventricular mass and daytime and night-time blood pressures: a meta-analysis of comparative studies. J Hypertens. 1995;13(8):823-829.

25. Verdecchia P, Schillaci G, Guerrieri M, et al. Circadian blood pressure changes and left ventricular hypertrophy in essential hypertension. Circulation. 1990;81(2):528-536.

26. Cao Y, Zhao S, Luo L. [Correlation between blood pressure variability and left ventricular hypertrophy in patients with primary hypertension.] Hunan Yi Ke Da Xue Xue Bao. 2002;27(3):253-255. [Chinese.]

27. Pai AU, Chakrapani M, Bhaskaran U, Kamath P. Study of homemonitored night blood pressure and its correlation with left ventricular hypertrophy in treatment-naive hypertensive patients. Singapore Med $J$. 2012;53(2):95-98

28. Sega R, Facchetti R, Bombelli M, et al. Prognostic value of ambulatory and home blood pressures compared with office blood pressure in the general population: follow-up results from the Pressioni Arteriose Monitorate e Loro Associazioni (PAMELA) study. Circulation. 2005;111(14):1777-1783.
29. Boggia J, Li Y, Thijs L, et al; for International Database on Ambulatory blood pressure monitoring in relation to Cardiovascular Outcomes (IDACO) investigators. Prognostic accuracy of day versus night ambulatory blood pressure: a cohort study. Lancet. 2007;370(9594):1219-1229.

30. Verdecchia P, Schillaci G, Reboldi G, de Simone G, Porcellati C. Original articles prognostic value of combined echocardiography and ambulatory blood pressure monitoring in hypertensive patients at low or medium cardiovascular risk. Ital Heart J. 2001;2(4):287-293.

31. Routledge FS, McFetridge-Durdle JA, Dean CR; for Canadian Hypertension Society. Night-time blood pressure patterns and target organ damage: a review. Can J Cardiol. 2007;23(2):132-138.

32. Ohkubo T, Hozawa A, Yamaguchi J, et al. Prognostic significance of the nocturnal decline in blood pressure in individuals with and without high 24-h blood pressure: the Ohasama study. J Hypertens. 2002; 20(11):2183-2189.

33. Dolan E, Stanton A, Thijs L, et al. Superiority of ambulatory over clinic blood pressure measurement in predicting mortality: the Dublin outcome study. Hypertension. 2005;46(1):156-161

34. Staessen JA, Thijs L, Fagard R, et al. Predicting cardiovascular risk using conventional vs ambulatory blood pressure in older patients with systolic hypertension. Systolic Hypertension in Europe Trial Investigators. JAMA. 1999;282(6):539-546.

35. Fagard RH, Thijs L, Staessen JA, Clement DL, De Buyzere ML, De Bacquer DA. Night-day blood pressure ratio and dipping pattern as predictors of death and cardiovascular events in hypertension. J Hum Hypertens. 2009;23(10):645-653.

36. Hermida RC, Calvo C, Ayala DE, López JE. Decrease in urinary albumin excretion associated with the normalization of nocturnal blood pressure in hypertensive subjects. Hypertension. 2005;46(4):960-968.

37. Hermida RC, Ayala DE, Fernández JR, Calvo C. Comparison of the efficacy of morning versus evening administration of telmisartan in essential hypertension. Hypertension. 2007;50(4):715-722.

38. Hoshino A, Nakamura $\mathrm{T}$, Matsubara $\mathrm{H}$. The bedtime administration ameliorates blood pressure variability and reduces urinary albumin excretion in amlodipine-olmesartan combination therapy. Clin Exp Hypertens. 2010;32(7):416-422.

39. Hermida RC, Calvo C, Ayala DE, et al. Treatment of non-dipper hypertension with bedtime administration of valsartan. J Hypertens. 2005; 23(10):1913-1922.

40. Sleight P, Yusuf S, Pogue J, Tsuyuki R, Diaz R, Probstfield J; for Heat Outcomes Prevention Evaluation (HOPE) Study. Blood-pressure reduction and cardiovascular risk in HOPE study. Lancet. 2001; 358(9299):2130-2131.

41. Svensson P, de Faire U, Sleight P, Yusuf S, Ostergren J. Comparative effects of ramipril on ambulatory and office blood pressures: a HOPE Substudy. Hypertension. 2001;38(6):E28-E32.

42. Taylor R. Conundrum of the HOPE study: time of taking ramipril may account for lack of relation between blood pressure and outcome. BMJ. 2003;327(7416):681-682

43. Hermida RC, Ayala DE, Fontao MJ, Mojón A, Fernández JR. Chronotherapy with valsartan/amlodipine fixed combination: improved blood pressure control of essential hypertension with bedtime dosing. Chronobiol Int. 2010;27(6):1287-1303.

44. Hermida RC, Ayala DE, Fernández JR, Calvo C. Chronotherapy improves blood pressure control and reverts the nondipper pattern in patients with resistant hypertension. Hypertension. 2008;51(1):69-76.

45. JCS Joint Working Group. Guidelines for the clinical use of 24 hour ambulatory blood pressure monitoring (ABPM) (JCS 2010): - digest version - Circ J. 2012;76(2):508-519.

46. Staessen JA, Byttebier G, Buntinx F, Celis H, O’Brien ET, Fagard R. Antihypertensive treatment based on conventional or ambulatory blood pressure measurement. A randomized controlled trial. Ambulatory Blood Pressure Monitoring and Treatment of Hypertension Investigators. JAMA. 1997;278(13):1065-1072.

47. Turgeon R, Allan GM. Taking blood pressure-lowering medications at night. Can Fam Physician. 2012;58(9):965. 
48. Padwal RS, Hemmelgarn BR, Khan NA, et al; for Canadian Hypertension Education Program. The 2009 Canadian Hypertension Education Program recommendations for the management of hypertension: Part 1 blood pressure measurement, diagnosis and assessment of risk. Can J Cardiol. 2009;25(5):279-286.

49. Verdecchia P, Angeli F, Mazzotta G, Gentile G, Reboldi G. Home blood pressure measurements will not replace 24-hour ambulatory blood pressure monitoring. Hypertension. 2009;54:188-195.
50. Xu T, Zhang Y, Tan XR. The dilemma of nocturnal blood pressure. J Clin Hypertens (Greenwich). 2012;14(11):787-791.

51. Stergiou GS, Nasothimiou EG, Destounis A, Poulidakis E, Evagelou I, Tzamouranis D. Assessment of the diurnal blood pressure profile and detection of non-dippers based on home or ambulatory monitoring. $\mathrm{Am}$ J Hypertens. 2012;25(9):974-978.

52. Parati G, Valentini M. Prognostic relevance of blood pressure variability. Hypertension. 2006;47(2):137-138.

\section{Publish your work in this journal}

Vascular Health and Risk Management is an international, peerreviewed journal of therapeutics and risk management, focusing on concise rapid reporting of clinical studies on the processes involved in the maintenance of vascular health; the monitoring, prevention and treatment of vascular disease and its sequelae; and the involvement of metabolic disorders, particularly diabetes. This journal is indexed on PubMed Central and MedLine. The manuscript management system is completely online and includes a very quick and fair peer-review system, which is all easy to use. Visit http://www.dovepress.com/ testimonials.php to read real quotes from published authors.

Submit your manuscript here: http://www.dovepress.com/vascular-health-and-risk-management-journal 